\title{
The Effect of Natural Antimicrobial Agents on Staphylococcus aureus and Escherichia coli Growth
}

\author{
Bazli Hilmi, ${ }^{1}$ Yazmin Bustami, ${ }^{2}$ Tatiya Trongsatitkul ${ }^{3,4}$ and Zuratul Ain Abdul Hamid ${ }^{1 *}$ \\ ${ }^{1}$ Biomaterials Research Niche Group, School of Materials and \\ Mineral Resources Engineering, Universiti Sains Malaysia, \\ Engineering Campus, 14300 Nibong Tebal, Pulau Pinang, Malaysia \\ ${ }^{2}$ School of Biological Sciences, Universiti Sains Malaysia, \\ 11800 USM Pulau Pinang, Malaysia \\ ${ }^{3}$ School of Polymer Engineering, Suranaree University of Technology, \\ Nakhon Ratchasima 30000, Thailand \\ ${ }^{4}$ Center of Excellence in Biomechanics Medicine, Suranaree University of Technology, \\ Nakhon Ratchasima 30000, Thailand \\ ${ }^{*}$ Corresponding author: srzuratulain@usm.my
}

Published online: 25 December 2019

To cite this article: Hilmi, B. et al. (2019). The effect of natural antimicrobial agents on Staphylococcus aureus and Escherichia coli growth. J. Phys. Sci., 30(Supp. 2), 55-63, https://doi.org/10.21315/jps2019.30.s2.5

To link to this article: https://doi.org/10.21315/jps2019.30.s2.5

\begin{abstract}
The purposes of this research are to study the effect of different natural antimicrobial agents and to evaluate their functional groups inhibition reactivity on bacterial growth. The investigated antimicrobial agents were aloe vera powder and citric acid. The evaluation of antimicrobial activity was done by using agar well diffusion method. The bacteria used for the assessment were Staphylococcus aureus (S. aureus) and Escherichia coli (E. coli). The functional groups were investigated by Fourier Transform Infrared (FTIR) spectroscopy. Only the antimicrobial agent citric acid showed significant inhibition towards both bacteria growth. The diameter of inhibition zone for $S$. aureus was larger compared to E. coli. The FTIR spectra showed the presence of functional groups only in citric acid agent. Citric acid has potential to be used as an alternative antimicrobial agent in the many applications including biomedical.
\end{abstract}

Keywords: Agar well diffusion, antimicrobial agent, Staphylococcus aureus, Escherichia coli, inhibition zone 


\section{INTRODUCTION}

Currently, the prevalence and the fast growth of drug- and antibiotic-resistant microorganisms have become a concern to public health. ${ }^{1}$ As been reported, in 2016, approximately 6 million people died around the globe because of infections of the upper respiratory tract, tuberculosis or diarrheal diseases. ${ }^{2}$ This large figure is contributed by the increase of the number of microorganism strains that are resistant to the existing drugs or antibiotics. For this reason, the value of antimicrobial becomes crucial and main focus of the researchers in order to counteract various human pathogens and treat microorganism-caused diseases. ${ }^{3}$ In addition, the exploitation of natural antimicrobial for this purpose should be prioritised over synthetic antimicrobial due to several reasons. Firstly, the use of synthetic chemicals for antimicrobial activity is limited due to their health and environmental hazard potential. ${ }^{4}$ Secondly, the multiplication of aggressive and endogenous microorganisms that are resistant to the existing synthetic antimicrobial agents. ${ }^{5}$ Thirdly, the society's reluctance to use the synthetic antimicrobial agents such as parabens which is known has potential hazards to human. ${ }^{6}$ Besides that, the natural antimicrobial agents are biocompatible or have better tolerance in the human body and the cost for preparation is lower compared to synthetic antimicrobial agents. ${ }^{1,7}$

A natural antimicrobial agent is defined as a substance from natural resources that kills or inhibits the growth of microorganisms such as bacteria, fungi and algae. ${ }^{8}$ In this research, citric acid and aloe vera were chosen as natural antimicrobial agents. Citric acid is known as a weak organic acid and usually crystallised into white grain at room temperature. It is found in many sources in citrus fruits such as lemons, orange and limes. It also possesses $\mathrm{pH}$ of 2 and biocompatible property. ${ }^{9}$ Aloe vera is known as a cactus-like plant that grows readily in hot and dry climates. ${ }^{10}$ Normally, aloe vera is extracted and processed into gel or powder before used in the research or study even in the industrial scale for food, medicine and cosmetic applications. ${ }^{11}$ Aloe vera contains anthraquinones, a compound that is believed and have proven to be effective in antimicrobial activity. ${ }^{12}$ Aloe vera powder has been reported to have antibacterial property which inhibited the growth of Pseudomonas aeruginosa (P. aeruginosa), Escherichia coli (E. coli) and Staphylococcus aureus (S. aureus).${ }^{13}$ Hence, the objectives of this research are to evaluate and study the effect of antimicrobial agents, namely citric acid and aloe vera powder on bacteria $S$. aureus and $E$. coli growth and to detect the functional groups that present in both antimicrobial agents. S. aureus and E. coli are the major cause of various human and animal infections and diseases. $S$. aureus is a gram-positive bacterium with coccus-shaped that is normally found on the skin and respiratory tracts of humans while $E$. coli is a gram-negative bacterium with rod-shaped that is normally found 
in the lower intestine of warm blooded organisms. ${ }^{14,15}$ The hypotheses are both natural antimicrobial agents inhibit the growth of both types of bacteria and the zone of inhibition on bacterium $S$. aureus is larger than $E$. coli as well as the infrared spectra exhibit the characteristic peaks indicating functional groups of both agents.

\section{EXPERIMENTAL}

\subsection{Materials}

Citric acid was purchased from Sigma Aldrich (M) Sdn. Bhd. and this material was in white crystal granules. Aloe vera freeze-dried powder was purchased from Tropical Bioessence Sdn. Bhd., Malaysia. Mueller-Hinton agar powder was purchased from Oxoid Ltd. and this material was in fine brown powder form. S. aureus (ATCC12600) and E. Coli (ATCC25922) strains were obtained from the School of Biology, Universiti Sains Malaysia (USM).

\subsection{Methods}

Agar well diffusion method is usually used to evaluate the antimicrobial activity of antimicrobial agents by detecting the inhibition zone and measuring its diameter. This test was conducted by following the method previously described by Semeniuc et. al. ${ }^{16}$ Firstly, both antimicrobial agents were dissolved in distilled water and shaken overnight in order to get $100 \mathrm{mg} \mathrm{ml}^{-1}$ concentration. An amount of $19 \mathrm{~g}$ of agar powder was dissolved in $500 \mathrm{ml}$ distilled water and then was autoclaved for $1 \mathrm{~h}$ at $120^{\circ} \mathrm{C}$. After autoclave process, the agar was cooled for $1 \mathrm{~h}$ at about $45^{\circ} \mathrm{C}-50^{\circ} \mathrm{C}$ and poured into the agar plates. The $8.5 \mathrm{~cm}$ diameter of agar plates required approximately $25 \mathrm{ml}$ of the agar medium or about $2 / 3$ of the height of agar plates. The four holes with a diameter of $9 \mathrm{~mm}$ were punched aseptically with a sterile corks borer at the cooled agar. The entire agar surface was inoculated by spreading a volume of the microbial (E. coli and $S$. aureus.) inoculum by using cotton wool. An amount of $100 \mu$ of the antimicrobial agent solution was pipetted into the hole accordingly. Then agar plates were incubated overnight at $37^{\circ} \mathrm{C}$. The antimicrobial agent diffuses in the agar medium and inhibits the growth of the microbial strain. The zone of inhibition was detected and its diameter was measured. Three replicates of agar plate were conducted to get the accurate results.

Chemical functional groups and bonds of both antimicrobial agents were identified by using Perkin-Elmer spectrometer 2000 FTIR (Bruker Vector 33, United States). Approximately $10 \mathrm{mg}$ of the agent powder was crushed and mixed with $100 \mathrm{mg}$ grounded spectroscopic grade of potassium bromide $(\mathrm{KBr})$ by using agate mortar. 
Then, the powder was pressed to make a transparent thin disk. The disk was subjected to FTIR spectra measured in the range of $4000 \mathrm{~cm}^{-1}$ to $550 \mathrm{~cm}^{-1}$ with average of four scans.

\section{RESULTS AND DISCUSSION}

Antimicrobial properties of citric acid and aloe vera have been investigated and the results are shown in Figures 1 and 2. As indicated by label A in Figure 1 and $\mathrm{B}$ in Figure 2, only citric acid agent showed a zone of inhibition on both bacteria $S$. aureus and E. coli growth, respectively. This is believed to occur due to highly germicidal property of citric acid besides its biocompatibility. ${ }^{17}$ According to Vasseur et al., citric acid had good antimicrobial activity and showed high inhibitory effect because of its ability to flow through the cell membrane. ${ }^{18}$ This is in agreement with Mani-López et al., who stated that citric acid was able to diffuse through the cell membrane and lowering the intracellular $\mathrm{pH} .{ }^{19}$ The low $\mathrm{pH}$ within the cell would cause damage to extracellular membranes, proteins and deoxyribonucleic acid (DNA) as well as disturb cell's enzymatic activities, thus leading to microorganism death. Unfortunately, illustrations A in Figures 1 and B in Figure 2, respectively, show no inhibition zone for aloe vera powder agent on both bacteria growth. This contradicts the finding reported by Robson et al., who stated that aloe vera dried powder showed more effective antibacterial activity as compared to fresh aloe vera. ${ }^{20}$ However, this result agreed with the previous work done by Tambekar et al. who found that the tested aloe vera powder showed no antibacterial activity towards several bacteria such as E. coli, S. aureus, $P$. aeruginosa, Proteus vulgaris (P. vulgaris), and Salmonella typhimurium (S. typhimurium) ${ }^{21}$ This occurred because the process and procedure for preparing aloe vera powder including extraction, heat treatment, filtration, and drying technique might disturb, change, or remove the ingredients or components for antimicrobial activity. ${ }^{1,22}$

In Figures 1 and 2, $d$ indicates the diameter of inhibition zone from citric acid agent on both $S$. aureus and E. coli bacteria, respectively. As can be seen, the average diameter of inhibition zone towards $S$. aureus bacterium $(26.33 \mathrm{~mm})$ was larger as compared to $E$. coli bacterium $(21 \mathrm{~mm})$ indicating that $S$. aureus was more sensitive and less resistant to citric acid compared to $E$. coli. This result is in parallel with Trombetta et al., who stated that gram-negative bacteria were generally more resistant to antimicrobial agent than gram-positive bacteria. ${ }^{23}$ This difference is also assumed to be due to different structure of cell walls of both bacteria. Grampositive bacteria's cell wall mostly consists of peptidoglycan and this structure allows antimicrobial molecules to easily penetrate the cell. Consequently, the molecules act within the cytoplasm as well as on the cell wall and leading to 
bacteria death. ${ }^{19,24}$ On the other hand, the cell wall of gram-negative bacteria is more complex as it contains an outer membrane covering its thin peptidoglycan layer. This outer membrane composes of a double layer of phospholipids that is linked to inner membrane by lipopolysaccharides (LPS). These outer membranes and LPS allow only small hydrophilic antimicrobial molecules to pass through and affect the bacteria. These features make gram-negative bacteria are more resistant to antimicrobial agent. ${ }^{25-27}$

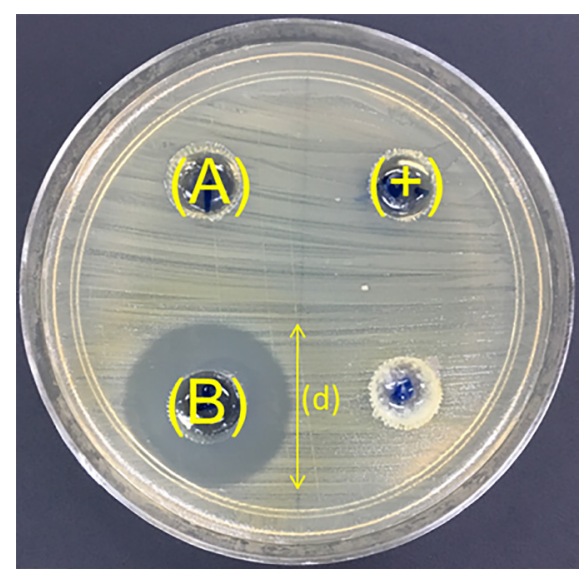

Figure 1: Aloe vera powder (A) exhibited no inhibition zone while citric acid (B) exhibited zone of inhibition on bacterium S. aureus growth. Distilled water $(+)$ indicates positive control and (d) indicates diameter of inhibition zone.

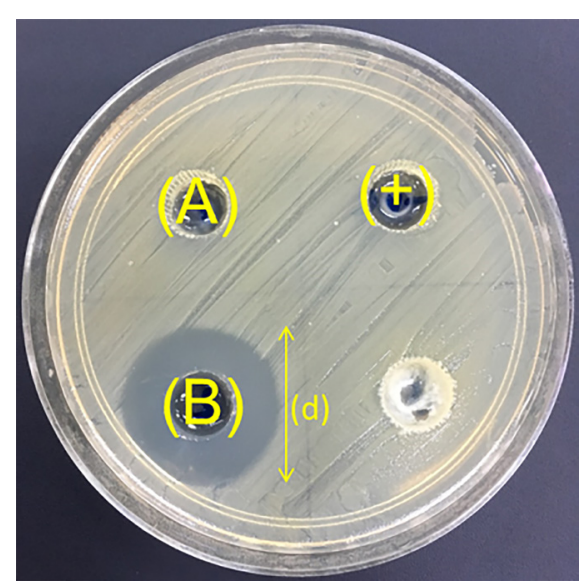

Figure 2: Aloe vera powder (A) exhibited no inhibition zone while citric acid (B) exhibited zone of inhibition on bacterium E. coli growth. Distilled water $(+)$ indicates positive control and (d) indicates diameter of inhibition zone. 
The spectrum of antimicrobial agent citric acid powder with characteristic peaks is shown in Figure 3. The strong peak at $1722 \mathrm{~cm}^{-1}$ indicates carboxyl $(\mathrm{C}=\mathrm{O})$ functional group and the peak at $1401 \mathrm{~cm}^{-1}$ indicates carboxyl $(\mathrm{C}-\mathrm{O}-\mathrm{H})$ functional group in plane bend. ${ }^{28}$ Citric acid is also known as an organic carboxylic acid and it is believed that the unreacted carboxyl groups of citric acid responsible for antimicrobial activity by reducing the bacteria's local $\mathrm{pH} .{ }^{29}$ The reduction of local $\mathrm{pH}$ may lead to the change of permeability of bacterial membrane, thus affecting their substrate transportation and leading to bacterial death. ${ }^{19,30}$ The spectrum proves the presence of carboxyl functional groups in the citric acid powder.

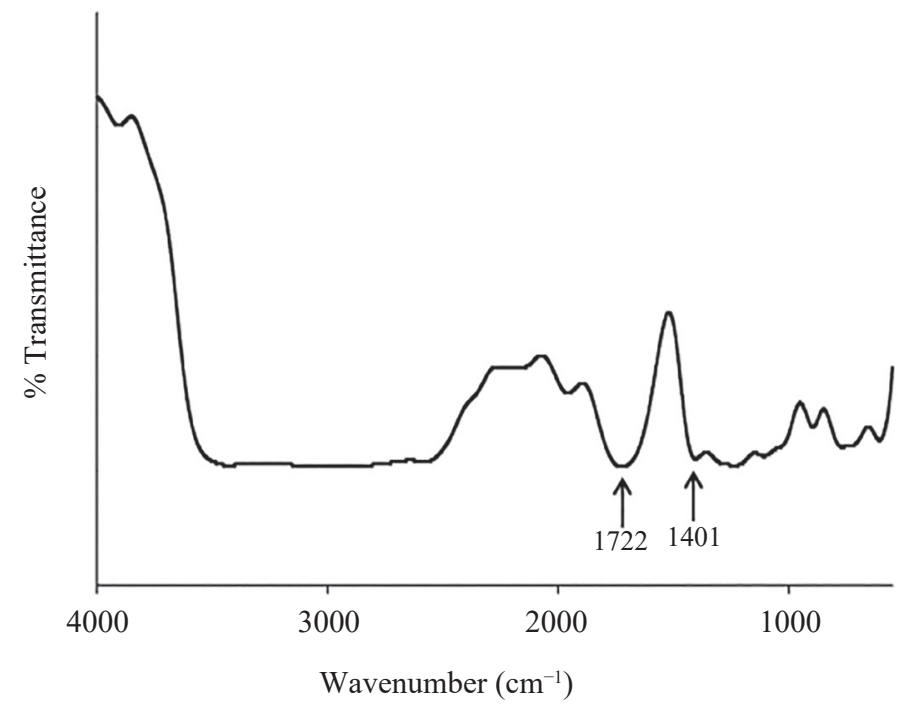

Figure 3: FTIR spectrum of antimicrobial agent citric acid powder.

Figure 4 shows the spectrum of antimicrobial agent aloe vera powder. According to the spectrum, there were no peaks detected the regions $1612 \mathrm{~cm}^{-1}$ and $1378 \mathrm{~cm}^{-1}$ where the $\mathrm{C}=\mathrm{C}$ stretching of aromatic ring and $\mathrm{C}-\mathrm{O}$ bonding of the anthraquinones should take the places respectively. ${ }^{31}$ This is believed to occur due to the process of preparing aloe vera powder which may lose the anthraquinones compound that play the role of antimicrobial component of aloe vera agent. ${ }^{1,22}$ This will support the result of no zone of inhibition detected for both bacteria growth. 


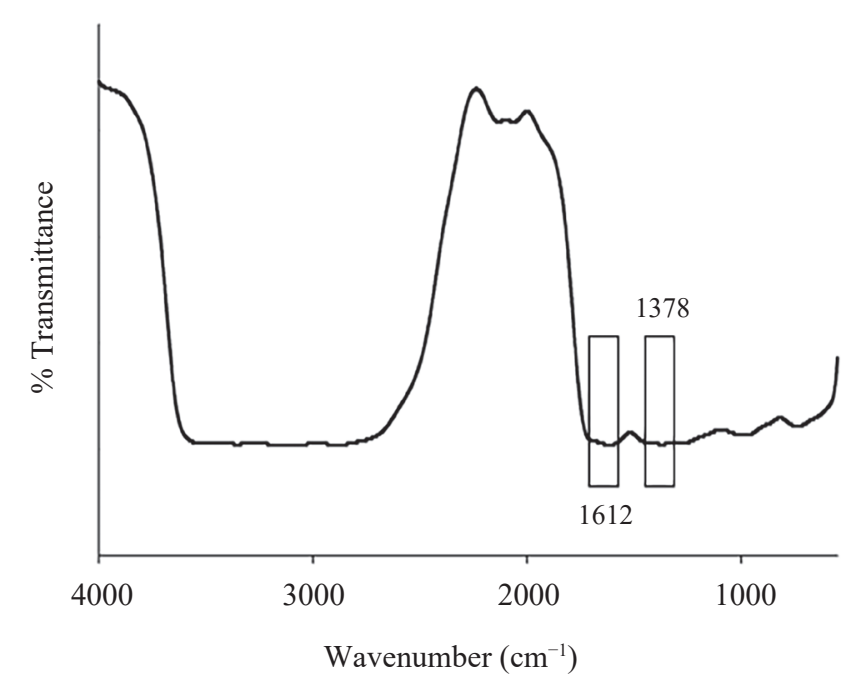

Figure 4: FTIR spectrum of antimicrobial agent aloe vera powder.

\section{CONCLUSION}

The present study showed that only citric acid agent had antimicrobial effect on both bacteria $S$. aureus and $E$. coli growth while aloe vera powder agent showed no antimicrobial activity. The average diameter of inhibition zone on $S$. aureus bacterium $(26.33 \mathrm{~mm})$ was larger than $E$. coli $(21 \mathrm{~mm})$ suggesting that $S$. aureus was more sensitive and less resistant to citric acid as compared to E. coli. The characteristic peaks were detected in citric acid powder spectrum only and not in aloe vera powder spectrum. Thus, citric acid showed good antimicrobial activity and has potential to be used as antimicrobial agent in many applications including biomedical.

\section{ACKNOWLEDGEMENTS}

The authors would like to thank USM for the financial support through Bridging Grant (304/PBAHAN/6316233). 


\section{REFERENCES}

1. Cock, I. E. (2008). Antimicrobial activity of Aloe barbadensis miller leaf gel components. Int. J. Microbiol., 4(2), 1-13.

2. Wińska, K. et al. (2019). Essential oils as antimicrobial agents-myth or real alternative? Mol., 24(11), 2130-2146, https://doi.org/10.3390/molecules24112130.

3. Rudramurthy, G. R. et al. (2016). Nanoparticles: Alternatives against drugresistant pathogenic microbes. Mol., 21(7), 836, https://doi.org/10.3390/ molecules21070836.

4. Mulyaningsih, S. et al. (2010). Synergistic properties of the terpenoids aromadendrene and 1,8-cineole from the essential oil of Eucalyptus globulus against antibiotic-susceptible and antibiotic-resistant pathogens. Phytomed., 17(13), 1061-1066, https://doi.org/10.1016/j.phymed.2010.06.018.

5. Nazzaro, F. et al. (2017). Essential oils and antifungal activity. Pharm., 10, 86, https://doi.org/10.3390/ph10040086.

6. Sharifi-Rad, M. et al. (2008). Salvia spp. plants: From farm to food applications and phytopharmacotherapy. Trends Food Sci. Technol., 80, 242-263, https://doi. org/10.1016/j.tifs.2018.08.008.

7. Liu, Q. et al. (2017). Antibacterial and antifungal activities of spices. Int. J. Mol. Sci., 18, 1283, https://doi.org/10.3390/ijms18061283.

8. Burnett-Boothroyd, S. C. \& McCarthy, B. J. (2011). 13-Antimicrobial treatments of textiles for hygiene and infection control applications: An industrial perspective. Cambridge: Woodhead Publishing.

9. Scelza, M. F. et al. (2004). Effect of three different time periods of irrigation with EDTA-T, EDTA, and citric acid on smear layer removal. Oral Surg. Oral Med. Oral Pathol. Oral Radiol. Endod., 98, 499-503, https://doi.org/10.1016/j. tripleo.2004.03.027.

10. Suleyman, A. \& Sema, A. (2009). Investigation of in vitro antimicrobial activity of Aloe vera juice. J. Anim. Vet. Adv., 8(1), 99-102.

11. Rahman, S., Carter, P. \& Bhattarai, N. (2017). Aloe vera for tissue engineering applications. J. Funct. Biomater., 8(1), 6, https://doi.org/10.3390/jfb8010006.

12. Banu, A. (2012). Efficacy of fresh aloe vera gel against multi drug resistant bacteria in infected leg ulcers. Aus. Med. J., 5, 305-309, https://doi.org/10.4066/ AMJ.2012.1301.

13. Sukarti, T. E., Sukarminah, M. T. \& Rianto. (2003). Effect of drying temperature on antibacterial characteristic of aloe vera cortex powder. Paper presented at the National Seminar and Annual Meeting of Indonesian Food Technologist Association (PATPI), Yogyakarta, 22-23 July.

14. Bachir Raho, G. \& Abouni, B. (2015). Escherichia coli and Staphylococcus aureus most common source of Infection. Badajoz: Formatex Research Center.

15. Flatamico, P. \& Smith, J. (2006). Escherichia coli infections. London: Elsevier.

16. Semeniuc, C. A. et al. (2017). Antibacterial activity and interactions of plant essential oil combinations against gram-positive and gram-negative bacteria. J. Food Drug Anal., 25(2), 403-408, https://doi.org/10.1016/j.jfda.2016.06.002. 
17. Georgopoulou, M., Kontakiotis, E. \& Nakou, M. (1994). Evaluation of the antimicrobial effectiveness of citric acid and sodium hypochlorite on the anaerobic flora of the infected root canal. Int. Endod. J., 27, 139-143, https://doi. org/10.1111/j.1365-2591.1994.tb00243.x.

18. Vasseur, C. et al. (1999). Effect of osmotic, alkaline, acid or thermal stresses on the growth and inhibition of Listeria monocytogenes. J. Appl. Microbiol., 86, 469476, https://doi.org.10.1046/j.1365-2672.1999.00686.x.

19. Mani-López, E. et al. (2012). Organic acids as antimicrobials to control Salmonella in meat and poultry products. Food Res. Intern., 45, 713-721, https://doi.org/10.1 080/03079457.2013.782097.

20. Robson, M. C. et al. (1982). Myth, magic, witchcraft or fact? Aloe vera revisited. J. Burn Care Rehab., 3, 157-162.

21. Tambekar, D. H. et al. (2007). Studies on antibacterial potential of Aloe vera fresh gel, latex and commercially available powders. Nat. Prod. Indian J., 3(2), 73-76.

22. Atherton, P. (1997). Aloe vera: Myth or medicine? Pos. Health, 1(4), 20-29.

23. Trombetta, D. et al. (2005). Mechanisms of antibacterial action of three monoterpenes. Antimicrob. Agents Chemother., 49, 2474-2478, https://doi. org/10.1128/AAC.49.6.2474-2478.2005.

24. Tiwari, B. K. et al. (2009). Application of natural antimicrobials for food preservation. J. Agric. Food Chem., 57, 5987-6000, https://doi.org/10.1021/ jf900668n.

25. Iscan, G. et al. (2002). Antimicrobial screening of Mentha piperita essential oils. J. Agric. Food Chem., 50(14), 3943-3946, https://doi.org/10.1021/jf011476k.

26. Nikaido, H. (1994). Prevention of drug access to bacterial targets: permeability barriers and active efflux. Sci., 264, 382-388, https://doi.org/10.1126/ science. 8153625 .

27. Vaara, M. (1992). Agents that increase the permeability of the outer membrane. Microb. Rev., 56, 395-411.

28. Acheampong, A. et al. (2018). Antioxidant, antimicrobial and FTIR analysis of methanol root extract of Cnestis ferruginea and ethanol root extract of Citrus limon. J. Pharm. Phyt., 7(4), 2938-2946.

29. $\mathrm{Su}, \mathrm{L}-\mathrm{C}$. et al. (2014). Study on the antimicrobial properties of citrate-based biodegradable polymers. Front. Bioeng. Biotechnol., https://doi.org/10.3389/ fbioe.2014.00023.

30. Bischof, V. S. et al. (2011). Cotton textiles modified with citric acid as efficient anti-bacterial agent for prevention of nosocomial infections. Croat. Med. J., 52, 68-75, https://doi.org/10.3325/cmj.2011.52.68.

31. Edward, D. S. \& Vaitheeswaran, M. (2014). FT-IR and GC-MS determination of bioactive constituents of Aloe barbadensis miller (Liliacae). World J. Pharm. Pharm. Sci., 3(5), 749-758. 